\title{
Challenges of the Bitcoin in the Arabic Countries
}

\author{
Nsreen Shetewy $^{1 *} \quad$ Jamal Aitlaadam $^{2 *} \quad$ Li Jun Jiang ${ }^{1 *}$ \\ 1.School of Economics, Jilin University, 2699, Qian Jin Da Jie, Changchun, P. R. China \\ 2.School of International Public Affairs SIPA, Jilin University, 2699, Changchun, P. R. China
}

\begin{abstract}
Recently, the world has seen the emergence of new phenomenal technology named crypto currency (Bitcoin) which is attracted to several international networkers across the globe. Yet, the Bitcoin was the online currency which is replaced the hard currency in a business online transaction and was accepted only by internet users so far. Though, this invisible currency was not allowed or even accepted in Arab world society because of religious circumstances or governmental consent. In this study, we tried to analyze the real challenges and necessitates that face the Bitcoin in the Arabian region. Therefore, the outcomes have been found that Islamic business rules somehow have restricted the using of the Bitcoin process in financial transactions. Furthermore, the lowest and highest service cost of internet represent the key consequences behind lessen of using Bitcoin. According to Google trends Data from 2013 to 2019, many Arabian-individuals did not know or even unfamiliar with the use of Bitcoin. Keywords: key words, Bitcoin; Arabic countries; Islamic; Internet services
\end{abstract}

DOI: $10.7176 / \mathrm{JESD} / 10-6-18$

Publication date:March $31^{\text {st }} 2019$

\section{Introduction}

From more than decades ago, the researchers and money experts have been started creating the virtual currency, which is used among financial business institutions. This sort of commercial currency was seen or appeared prior by Chaum. Who has been published a paper in 1982 then Wei Dan in 1998 (Singhal and Rafiuddin 2014), (Singhal and Rafiuddin 2014), but all these attempts got failed. In November 2008, Satoshi Nakamoto suggested to Bitcoin in white paper, and in 2009 his idea (became) interpreted into reality (Grant, Hogan et al. 2015). In fact, Bitcoin is one of cryptocurrency that has a digital entity and computer code on the Internet. Anyone can access and get Bitcoin from several ways as the following methods (i) purchasing electronic shares (ii) selling online products and accepting Bitcoin as a payment mechanism, (iii) by mining easy money.

Nowadays, Bitcoin price rate has been changed remarkably time to time. Where, change the price within $500 \%$ For instance, since the first purchase operation deals with two pizzas by 10,000 BTC in 2010.Untill that a period the prices increased more than expectedly the average in using the Bitcoin around November-2018 to $\$ 6.400$.

Additionally, Bitcoin on the field of network processing is seen as approximately 356 million BTC with total wallet users approximately 30 million user count (https://blockchain.info). That make Bitcoin attracts attention to many online sectors, which end up into supporters and opponents of it. Indeed, Supporters of the Bitcoin are used coin in peer-to-peer online transactions ( $\mathrm{p} 2 \mathrm{p})$. Which allow directed transaction goes between two parts without a third party as a mediator (Nakamoto 2008). Besides, low transaction cost, transparency, maintaining the confidentiality of data, and ability to the use it from anytime and anywhere else. On the other hand,(Bouoiyour and Selmi 2016), (Jiang, Nie et al. 2018) (Baur, Hong et al. 2018) seen Bitcoin is improper online sources of volatile, unstable, and it encourages illegal activities which is truly untraceable and unsupported by government.

Indeed, in the Arab countries, Bitcoin is still in a nascent stage, where most countries is not regulate or allowed to the usage of Bitcoin in trading. However, only, the UAE initiated and promotes on a spread technology Blockchain that is opened the door for using technology Blockchain in public and privet sectors. Despite, the announcement of the UAE Central Bank in January 2017, by working on use technology Blockchain for planning to make Dubai smart city by 2020. But February 2017, the Governor of the UAE Central Bank has clarified that "these regulations do not apply for Bitcoin or other cryptocurrencies" so Bitcoin is still illegal(Singhal and Rafiuddin 2014),(Hezeem 2018) and is backed by no legal governmental institute.

For such countries like Lebanon, Saudi Arabia, and Morocco, individuals were warned from using Bitcoin in the commercial trading. In addition, in Egypt, particularly, the Grand Mufti has been issued a fatwa prohibiting the use of Bitcoin in Financial or commercial transactions because it is incompatible with the Islamic-perspective (where it is not compatible with Islamic frameworks In January 2018). In fact, there are few studies are interested in the status of Bitcoin in the Arab region. Therefore, this study will be contribution in the literature.

\section{How do you Get Bitcoin?}

Although, Bitcoin is a digital entity recorded a its speedy transactions on the Internet, and it is divided into small units (Tan and Low 2017) but there are several measures and ways to acquire it. First by buying, Second by selling commercial products and accepting and recording Bitcoins transactions as a sort of payment mechanism, 
Third by mining the Block chains (Turpin 2014). Furthermore, any internet user can do mining when they have accessed computer and programmers software for quick encrypted cash process. Initially, miners Bitcoin need to check and validate transactions process and did not use before (Ciaian, Rajcaniova et al. 2016) (Shi 2016). The validated and checked ones are very important to avoid the double-spending problem. Which is indicated by Satoshi Nakamoto research for a solution methods of so called "Double Spending Problem" by record all transactions in public ledger. That is cannot be changed it (Nakamoto 2008, Albuquerque and Callado 2015). After that, many miners use certain software to access the new block puts on Blockchain, then the computer's connection would work automatically on solving transactions processing capacity labeled as algorithm. The mathematics problem be difficult with the time, and the transaction giants Bitcoin need high electricity and time for get it.(Böhme, Christin et al. 2015).

Despite, the recent period witnessed high significant unexpected prices but suddenly declined again to reach \$6400in November 2018 with a drop rate of approximately 3:1 in commercial market price. Indeed, Bitcoin is volatility, in making difficulties and controversies in predicting Bitcoin high rate prices under global business policies.

https://blockchain.info/charts/market-price?timespan=all

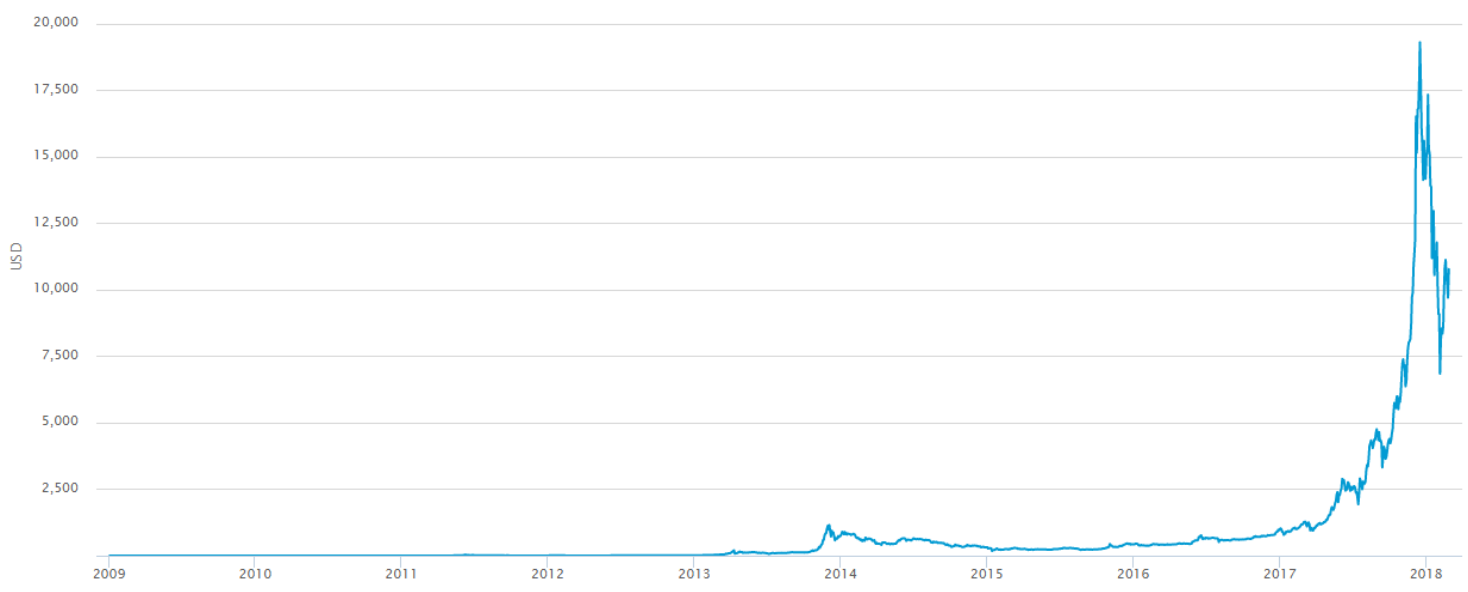

Figure 1 Bitcoin prices (2013-2018).

\section{Challenges of the Bitcoin in the Arab Countries}

Bitcoin as a new network technology, it did not receive significant attention from researchers and experts in the Arab countries. Because of the lack of good internet speed and unavailable organized database, also it has been discovered that the accreditation on the descriptive methods is more efficient and able to determine the obstacles that prevent the Bitcoin from online commercial trading across the Arab world. .Thus, Here's some of specified main obstacles that are facing Bitcoin in the Arab world countries based on three dimensions:

\subsection{The religious Dimension (Al Shariah)}

In the light of Islamic religious dimension (Al Shariah, see note) that is one of the fundamental resources of religious legislation which is regulate and operate financial transactions process in the Arab world. Accordingly, the vast controversy around acceptance the Bitcoin or rejecting it as one of illegal benefiting aspect in Islamic trading perspective. According to the Al Shariah, the use of any tool like money should have the desirability, storability and thamaniyyah (the meaning of thamaniyyah is an independent standard of value + a unit of account). From this perspective, the Shariah scholars have been divided their opinions regarding Bitcoin as the following: First, Bitcoin is not money (Mal) and it used only for intangible commercial trading transactions among internet users which is consider as a non - shariah compliant investment. Second: it is not money (Mal)(Adam, 2017).

3.1.1 Bitcoin opponents

The first opinion which prohibited use of the Bitcoin indicates that Bitcoin has no physical form but only digital numbers are entered or signed in a Blockchain on the network process. In addition, it is using for speculation, therefore Bitcoin is not real money. Similarly, Bitcoin using in speculations because it has high volatility prices so far, Bitcoin is kind of Maysir. According to these factors, Bitcoin is not the right tangible currency can be used or accepted in the Islamic dimension as one of the financial instruments and business transactions which surely makes Bitcoin as an illegal tool.(Adam, 2017).

On the same words, the owner of Bitcoin is unknown, so it is difficult to identify the account user whom the person is involved in Bitcoin transactions or not. Also, it still hard to check other individuals who are involving in the same bitcoin transaction process.

In addition, Bitcoin still has no certain fiscal identification as more used in internet market due to the value 
of Bitcoin is not restricted with any tangible asset. According to previous reasons, Bitcoin is compatible with case uncertain (Gharar,) which is prohibited in Islamic trading rules. Thus, Bitcoin is unacceptable from the Islamic perspective (Bakar et al., 2017). ). On the other hand, the Islamic dimension promotes the circulation of wealth and prohibits the hoarding it and speculation. Rather, Bitcoin fails in the aspect of marketability and circulation because the Bitcoin investors have to hoard and hold Bitcoin instead of spending it, making Bitcoin illiquid. Moreover, Bitcoin is not acceptable because of the fact that the lack of a regulatory framework on workingmechanism of Bitcoin is fully cryptic in the network arena that leads to unbeneficial outcomes. Furthermore, the complex nature of Bitcoin opens the door into dark users such as hackers and fraudsters. Therefore, the wealth is not safe enough (Adam, 2017).

3.1.2 Bitcoin supporters

The second opinion which agreed the Bitcoin indicates that Bitcoin is more Halal currency in Islam compared to other currency (Muedini, 2018). They said it is not similar to the precious things or other coins. It is able to avoid the problem of Riba forbidden in financial transactions because Bitcoin depends on the proof of work, not on the principle of debt as other currencies (Evans and Finance, 2015). The storability due to the nature of the Bitcoin, which can be stored in a public ledger on Blockchain, and ability ownership Bitcoin on, uses it by two keys. First one is public and anyone can send Bitcoin to the key number, second one secret key, just the person has just ownership Bitcoin can use it (Mann and Loebenberger, 2017) (Adam, 2017). Although the Bitcoin is merely digits there is no evidence which indicates to it is illegal. Given the maximum number of Bitcoin in Blockchain is 21 million units that solve the inflation problems because no individual or government can do anything to change it. As a result, the creation of new Bitcoin is done by spending real assets (mining) not as a result of printing new money so price volatility of Bitcoin is a result of the exchange between the trades not because of government inflation (Chaim and Laurini, 2018). Finally, for money transfer transaction, Bitcoin no needs height cost for transfer the money compared with other currency, addiction ensures ownership currency by $100 \%$, also able to use it anywhere and at any time.

\subsection{Internet}

Recently, the internet becomes a globally connected network system as well as one of the important factors in making the world interacted and well developed. On the Arab side, 22 countries have been started using internet network in the mid-1990s by few numbers of users (Alshahrani, 2016; Salem et al., 2014). Then, some countries (Gulf countries) have been worked on the improvement of communications internet sector, while other countries still struggling to develop their infrastructure and access networking of the internet. Therefore, since ten years ago, Arabic countries experienced a big improvement in the number of internet users (Khazaal et al., 2011). Where in 2011 the number of internet users in the Arab world has reached more than 135 million users. Then, the number grow-fast to approximately173 million users in 2017. Despite development efforts, the real number of internet users is equal to $49 \%$ of the total population. That means more than half population cannot use the internet, according to World Bank data in table 1 could divide Arabic world into two parts, First, countries have high quality and easy internet users access (Alrawabdeh, 2009). While other countries are undeveloped for internet services, these countries are containing the largest percentage of the population. In general, the internet is the main tool for using Bitcoin. Since the high cost of internet services in Arab countries, the use of Bitcoin will be more limited and less accessing. After all, we think that Bitcoin needs time and knowledge for using it in the Arab world. In particular, the Mohammed bin Rashid School of Government has conducted a survey to identify the potential for individuals to be used bitcoin in financial transactions and has reached the highest level of uncertainty among individuals survey (Salem et al., 2014). 
Table (1) Internet users in the Arab world

\begin{tabular}{|c|c|c|c|c|c|c|c|c|c|c|c|c|c|c|}
\hline $\begin{array}{l}\text { Country } \\
\text { Name }\end{array}$ & $\begin{array}{l}\text { United } \\
\text { arab } \\
\text { emarat }\end{array}$ & Bahrain & Algeria & Egypt & Iraq & Jordan & Kuwait & Libya & Morocco & Oman & Qatar & $\begin{array}{l}\text { Saudi } \\
\text { Arabia }\end{array}$ & Yemen & Tunisia \\
\hline 2000 & 23.6 & 6.15 & 0.49 & 0.64 & & 2.62 & 6.73 & 0.19 & 0.69 & 3.52 & 4.9 & 2.2 & 0.09 & 2.8 \\
\hline 2001 & 26.3 & 15.0 & 0.65 & 0.84 & 0.1 & 4.71 & 8.55 & 0.4 & 1.37 & 5.9 & 6.17 & 4.7 & 0.09 & 4.3 \\
\hline 2002 & 28.3 & 18.1 & 1.59 & 2.72 & 0.5 & 6.03 & 10.3 & 2.3 & 2.37 & 6.9 & 10.3 & 6.4 & 0.5 & 5.3 \\
\hline 2003 & 29.5 & 21.6 & 2.19 & 4.04 & 0.6 & 8.47 & 22.4 & 2.8 & 3.4 & 7.3 & 19.3 & 8.1 & 0.6 & 6.5 \\
\hline 2004 & 30.1 & 21.5 & 4.64 & 11.9 & 0.9 & 11.7 & 22.9 & 3.5 & 11.7 & 6.8 & 20.7 & 10.2 & 0.9 & 8.5 \\
\hline 2005 & 40 & 21.3 & 5.85 & 12.8 & 0.9 & 12.9 & 25.9 & 3.9 & 15.1 & 6.7 & 24.8 & 12.7 & 1.05 & 9.7 \\
\hline 2006 & 52 & 28.2 & 7.38 & 13.7 & 0.9 & 13.9 & 28.8 & 4.3 & 19.8 & 8.29 & 28.9 & 19.5 & 1.3 & 12.99 \\
\hline 2007 & 61 & 32.9 & 9.45 & 16.03 & 0.9 & 20 & 34.8 & 4.7 & 21.5 & 16.7 & 37 & 30 & 5.01 & 17.1 \\
\hline 2008 & 63 & 51.9 & 10.2 & 18.0 & 1 & 23 & 42 & 9 & 33.1 & 20 & 44.3 & 36 & 6.9 & 27.5 \\
\hline 2009 & 64 & 53 & 11.2 & 20 & 1.1 & 26 & $\mathbf{5 0 . 8}$ & 10.8 & 41.3 & 26.8 & 53.1 & 38 & 9.9 & 34.1 \\
\hline 2010 & 68 & 55 & 12.5 & 21.6 & 2.5 & 27.2 & 61.4 & 14 & 52 & 35.9 & 69 & 41 & 12.4 & 36.8 \\
\hline 2011 & 78 & 77 & 14.9 & 25.6 & 5 & 34.9 & 65.8 & 14 & 46.1 & 48 & 69 & 47.5 & 14.9 & 39.1 \\
\hline 2012 & 85 & 88 & 18.2 & 26.4 & 7.1 & 37 & 70.5 & & 55.4 & 60 & 69.3 & 54 & 17.5 & 41.4 \\
\hline 2013 & 88 & 90 & 22.5 & 29.4 & 9.2 & 41.4 & 75.5 & 16.5 & 56 & 66.5 & 85.3 & 60.5 & 20 & 43.8 \\
\hline 2014 & 90.4 & 90.5 & 29.5 & 33.9 & 13.2 & 46.2 & 78.7 & 17.8 & 56.8 & 70.2 & 91.5 & 64.7 & 22.6 & 46.2 \\
\hline 2015 & 90.5 & 93.5 & 38.2 & 37.8 & 17.2 & 60.1 & 77.5 & 19.2 & 57.1 & 73.5 & 92.9 & 69.6 & 24.1 & 46.5 \\
\hline 2016 & 90.6 & 98 & 42.9 & 41.3 & 21.2 & 62.3 & 78.4 & 20.3 & 58.3 & 76.9 & 94.3 & 74.9 & 24.6 & 49.6 \\
\hline
\end{tabular}

Sources: world Bank

\subsection{People interested}

The rate of interested individuals on research about Bitcoin has to be low in the Arab countries. Where Google trends data referred to the low rate during the period 2013-2018. Except for the period from October 2017 to February 2018, which a significant rise recorded in prices. After that, the rate search has dropped again as presented it in Figure 2. It is surprising the figure indicates that the decline in the search rate went to most countries even the Gulf countries that has high technology. Clearly, the UAE, which has started to apply the technology of Blockchain in some sectors in the framework of planning to make Dubai the smart city by 2020. (Singhal and Rafiuddin, 2014). Nevertheless, it still has a low rate of the search for Bitcoin in the network. Rather, low interest of individuals of Bitcoin in the Arab countries maybe returns to ways and types of advertising of Bitcoin. Additionally, the Internet tools and English language for Bitcoin make it more difficult to deal with the usage of Bitcoin and the measures of accessing it. Especially, with a presence, approximately $65 \%$ of Internet users in the Arab region using the Arabic language as the main tool for searching on online. 


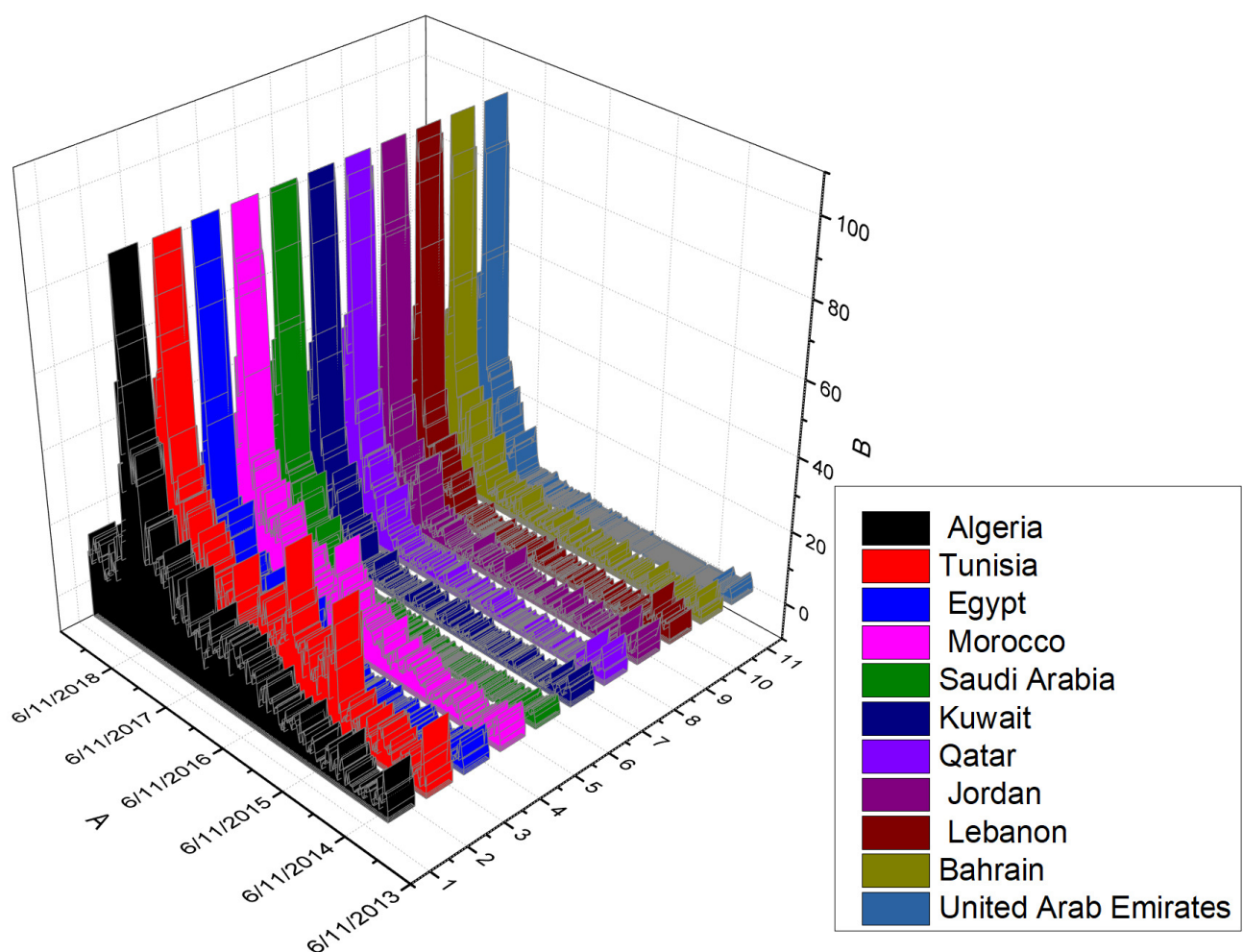

Figure 2. Google trends show interest in Bitcoin.

\section{Conclusion}

Bitcoin is a cryptocurrency trading assets in the online market, which has greatly enhanced the centralization of the bitcoin network process among national and international users since 2013 In this paper, we have specified the main obstacles and circumstances that are facing Bitcoin in Arab countries. Though, The Islamic-religion dimension (Shariah) scholars have been divided their opinions regarding Bitcoin between supporter and opponents. Then, highlighting the internet as a significant tool for using Bitcoin in the Arab world, which becomes one of the obstacles to access the world of Bitcoin. Additionally, Many Arabian people precisely have not idea about Bitcoin. For the future research, our work will introduce critical analysis and new statistics information includes the impact of the restrictions imposed by Arab governments on existing users of Bitcoin in the Arab world.

Note.

- Al Shariah Al Shariah In an Islamic context, the term can refer to the purposes of Islamic faith, or of the Qur'an and Sunnah's text(Chapra, 2016; Zahrah, 1963)

- Māl; there are five objectives of wealth (mal) or financial transaction, that is (1) continuity of the circulation of the wealth, (2) continuity of the investment of wealth, (3) achieving comprehensive communal prosperity, (4) financial transparency and validation of financial ownership(Chapra, 2016).

- Gharar is a word used to measure the legitimacy of a hazardous sale or risky investment pertaining to either short selling, the selling of goods or assets of uncertain quality or delivery, gambling or contracts that are not drawn out in clear terms. Generally, Gharar is prohibited in Islam.(Cattelan, 2009; Waemustafa and Suriani, 2016).

- Riba; can be roughly translated as "usury", or unjustified enrichment, forbidden on ethical grounds, exploitative gains made in business under Islamic law(Cattelan, 2009).

- Maysir is prohibited by Islamic law (Shariah), on the grounds that is the agreement between participants is based on immoral inducement provided by entirely wishful hopes in the participants' minds that they will gain by mere chance, with no consideration for the possibility of loss. (Cattelan, 2009).

- Halal and Haram; it is meaning lawful or permitted, the opposite of halal is haram, which means unlawful or prohibited. (Al-Qaradhawi and bin Daud, 2016; Zakaria, 2008)

\section{References}

Adam, M.F.J.A.F.C., 2017. Bitcoin: Shariah Compliant. 1-54.

Alrawabdeh, W.J.I.A.J.o.I.T., 2009. Internet and the Arab World: Understanding the Key Issues and Overcoming the Barriers. 6.

Alshahrani, H.A.J.T., 2016. A brief history of the Internet in Saudi Arabia. 60, 19-20. 
Bakar, N.A., S. Rosbi, K.J.I.J.o.M.S. Uzaki, B. Administration, 2017. Cryptocurrency Framework Diagnostics from Islamic Finance Perspective: A New Insight of Bitcoin System Transaction. 4, 19-28.

Baur, D.G., K. Hong, A.D.J.J.o.I.F.M. Lee, Institutions, Money, 2018. Bitcoin: Medium of exchange or speculative assets? 54, 177-189.

Bouoiyour, J., R.J.E.B. Selmi, 2016. Bitcoin: A beginning of a new phase. 36, 1430-1440.

Carneiro, H.A., E.J.C.i.d. Mylonakis, 2009. Google trends: a web-based tool for real-time surveillance of disease outbreaks. 49, 1557-1564.

Chaim, P., M.P. Laurini, 2018. Volatility and return jumps in bitcoin. Economics Letters 173, 158-163.

Choi, H., H.J.E.R. Varian, 2012. Predicting the present with Google Trends. 88, 2-9.

Corbet, S., B. Lucey, M. Peat, S. Vigne, 2018. Bitcoin Futures-What use are they? Economics Letters 172, 23 27.

Dyhrberg, A.H., S. Foley, J. Svec, 2018. How investible is Bitcoin? Analyzing the liquidity and transaction costs of Bitcoin markets. Economics Letters 171, 140-143.

Evans, C.W.J.J.o.I.B., Finance, 2015. Bitcoin in Islamic banking and finance. 3, 1-11.

Hezeem, A.B., 2018. The Impact of Blockchain, Cryptocurrencies

and Bitcoin in UAE.

https://blockchain.info.

Jiang, Y., H. Nie, W.J.F.R.L. Ruan, 2018. Time-varying long-term memory in Bitcoin market. 25, 280-284.

Kai Jie Shawn, L., D. Stridsberg, 2014. Feeling the Market's Pulse with Google Trends.

Khazaal, Y., A. Chatton, K. Atwi, D. Zullino, R. Khan, J.J.S.a.t. Billieux, prevention,, policy, 2011. Arabic validation of the compulsive internet use scale (CIUS). 6,32

Kristoufek, L.J.S.r., 2013. BitCoin meets Google Trends and Wikipedia: Quantifying the relationship between phenomena of the Internet era. 3, 3415.

Mann, C., D.J.I.J.o.I.S. Loebenberger, 2017. Two-factor authentication for the Bitcoin protocol. 16, 213-226.

Muedini, F.J.E.J.o.I.F., 2018. The Compatibility of Cryptocurrencies and Islamic Finance.

Nair, M., N.J.T.R.o.A.E. Cachanosky, 2017. Bitcoin and entrepreneurship: breaking the network effect. 30, 263275.

Nakamoto, S., 2008. Bitcoin: A peer-to-peer electronic cash system.

Salem, F., R. Mourtada, S. Alshaer, 2014. The Arab World Online 2014: Trends in Internet and Mobile Usage in the Arab Region. (Dubai: Mohammed Bin Rashid School of Government).

Singhal, A., A. Rafiuddin, 2014. Role of Bitcoin on Economy, Proceedings of the World Congress on Engineering and Computer Science.

Turpin, J.B.J.I.J.G.L.S., 2014. Bitcoin: The economic case for a global, virtual currency operating in an unexplored legal framework. 21, 335 .

Urquhart, A.J.E.L., 2018. What causes the attention of Bitcoin? 166, 40-44.

Yelowitz, A., M.J.A.E.L. Wilson, 2015. Characteristics of Bitcoin users: an analysis of Google search data. 22 , 1030-1036.

Al-Qaradhawi, Y., M.H. bin Daud, 2016. Halal dan haram dalam Islam. (PTS Publishing House Sdn. Bhd.).

Cattelan, V., 2009. From the concept of haqq to the prohibitions of riba, gharar and maysir in Islamic finance. International Journal of Monetary Economics and Finance 2, 384-397.

Chapra, M.U., 2016. The future of economics: An Islamic perspective. (Kube Publishing Ltd).

Waemustafa, W., S. Suriani, 2016. Theory of Gharar and its interpretation of risk and uncertainty from the perspectives of authentic hadith and the Holy Quran: Review of literatures. International Journal of Economic Perspectives 10, 1-27.

Zahrah, M.A., 1963. Tarikh al-madhahib al-Islamiyah. (Dār al-fikr al-'Arabī).

Zakaria, Z., 2008. Tapping Into the World Halal Market, Some discussions on Malaysian Laws and Standards. Jurnal Syariah 16, 603-616. 